\title{
Preference characteristics and influencing factors of students' consumption under the new media environment
}

\author{
Xinxin Liu ${ }^{1, a}$ \\ ${ }^{1}$ College of Humanities, Henan University of T C M, Zhengzhou, Henan 450046, China \\ aemail:xinxin_liu123@126.com
}

Keywords: New media; Conspicuous consumption; Consumer preferences; Reference group.

\begin{abstract}
Consumer preferences student population although rarely affected family members, but from peers, friends, real friends on the network, virtual friends but profound changes affecting their existing consumer preferences. A network questionnaires and paper questionnaires combination of 274 college students conducted interviews and questionnaire, consumer preferences that may have characterized this group in the new media environment is analyzed. Survey shows that college students there are currently 90 post conspicuous consumption preferences, interaction influence consumer preferences and propensity fake consumer preferences. Combined with the impact of new media consumption patterns, analyzes the influencing factors in the new media environment groups, consumer preferences change students.
\end{abstract}

\section{Introduction}

Universities Students should attach importance to training and shaping healthy consumer psychology and behavior, in order to contribute to the success of college students' academic pursuit [1-4]. Students proposed to cultivate good consumer psychology and behavior as an important part of campus culture [5]. Students design of the concept of consumer health topics in the cultural construction of campus activities, and perseverance [6]. Create a conservation-oriented campus concept, the environmental impact of the use of the campus Students develop a rational and healthy consumption habits, the formation of a good life style, healthy for society members with rational consumption habits of society.

Net purchase of normalization, in fact, not only reflected in the high volume of online shopping, more reflected in the growing wealth of online shopping product types, as long as the law allows goods within the scope of, almost all through online shopping achieve, online shopping has been deeply embedded in people's daily lives. Under the new consumer media environment, not only the online shopping platform as a simple shopping platform, can be used as information gathering platform, these platforms [7]. Consumers browse through other people's online shopping selection and experience, the formation of the trend of understanding, awareness of the brand image, as well as pricing is fair judgment. Traditional media age, consumers are called the audience, was seen as a passive acceptance of individual mass media advertising, and in the new media age, consumers are more and more called users, they can actively search, Discrimination, screening information on the different media platforms, form their own unique consumer awareness, and this is precisely rely on online shopping normalization accumulated vast amounts of data to achieve $[8,9]$.

The height of the popularity of mobile intelligent terminal in the student population, making them a chance to get real-time living conditions of those people with a certain social distance, geographic distance with them, the state consumer-related information, such information will affect their ongoing treatment specific brand, consumption patterns, and other aspects of payment options. In some special cases, film and television works in the virtual characters even consumer preferences also affect the student population, implanted into the story of the product, the brand will be the role of the character, a combination of taste, making consumers because it like a characters or unconscious imitation of role, and for some products, the brand produced a special preference.

\section{Students consumer preferences influence of new media factors}




\subsection{Multi-modal network use}

Multi-modal network uses a diversified state refers to the way people use the network, which means that the number of users involved in the network activity is not only a few [10]. According to Wei Lu et al study, if a person daily internet usage, an average of only two of them, then these two not receive e-mail, is to look at the news. If the person using the network every day on average there are six kinds of behavior, he began adding some social media application on the inside, such as reading a blog. If a multi-modal network uses a diversified state it refers to the way people use the network, which means that the number of users involved in the network activity is not only a few. According to Wei Lu et al study, if a person daily Internet usage, an average of only two of them, then these two not receive e-mail, is to look at the news. If the person using the network every day on average there are six kinds of behavior, he began adding some social media applications inside.

\subsection{Openness to data applications}

Many product innovation, service innovation under the new media environment are dependent on the application of large data, although public awareness for the protection of personal information is being gradually increased, but the general student population on rational use of user data, who are more open mind. They do not care about the business recommend similar goods according to their past consumption records, browsing history, reminding purchase or publish new product information again. In fact, many college students really enjoy this intimate style of service, especially in the network music player use, according to the user's listening record, download record recommend "guess you like," the song, is a very popular.

Such data based on user behavior and customizable reminder, push services, help enhance the user viscosity and loyalty to a particular platform, and for user data using an open mind is one of the important driving force to promote this kind of precision marketing. More and more college students not only willing to publicly record their behavior, location information, and sometimes even willing to share a link, others registration recommended way, with businesses gather more user information. QQ album launch requires the user to add the names of people in the photos, notes, information activities get a lot of support of users, although they knew the move not only enable Tencent to collect a lot of information about the user's name, but also to make personal information facial feature information matches, college students when adding the name information for their students did not show a strong resistance.

\subsection{From the reference group}

Era of traditional media, most people's reference group that neighbors, family, friends, classmates, colleagues and so on, people will refer these relatively familiar groups to adjust their lifestyles, consumer behavior. The new media age, some of the reference group from the distance of time and space with a certain social, and even some of the virtual reference groups are beginning to produce a variety of effects on people's consumption preferences. Consumers will not only be able to understand the movements of their own focus groups through various media platforms, there may even interact with them. In the new media age, not only the scope of the reference group was enlarged, with a certain social distance from the reference group and the temporal and spatial distance between the affected objects is greatly shortened, they, like their family members and friends as individual consumption exert direct influence preferences.

\section{Results and discussion}

\subsection{The proportion of total consumption of major consumer items}

Shopping under the new media allows consumers to fully understand the product performance, conduct price comparisons. With the development of new media, more and more students choose a more convenient online shopping. The popularity of online shopping has also increased at a certain college students consumption techniques, new media can make it easy to get consumer advice, you 
can view the properties of items when shopping, but also can read reviews of others for commodities. This shopping more convenient to shop around, but also more convenient Students make a choice.

As can be seen from the data in Fig. 1, the diet of expenditure living in the largest number of 300-500 yuan, a higher proportion of "food consumption" of total consumption, communications expenditure, $60 \%$ of people 50 to 100 yuan monthly bill around is not to be underestimated, 5 percent of the students in more than 100 yuan, it seems easier to buy a mobile phone with a cell phone said than done. Love consumption accounted for $6 \%$, about $7 \%$ of consumption to learn, it can be described as well-matched. The ratio is shown in Fig. 1 below.

\section{The proportion of major consumption items in total consumption}

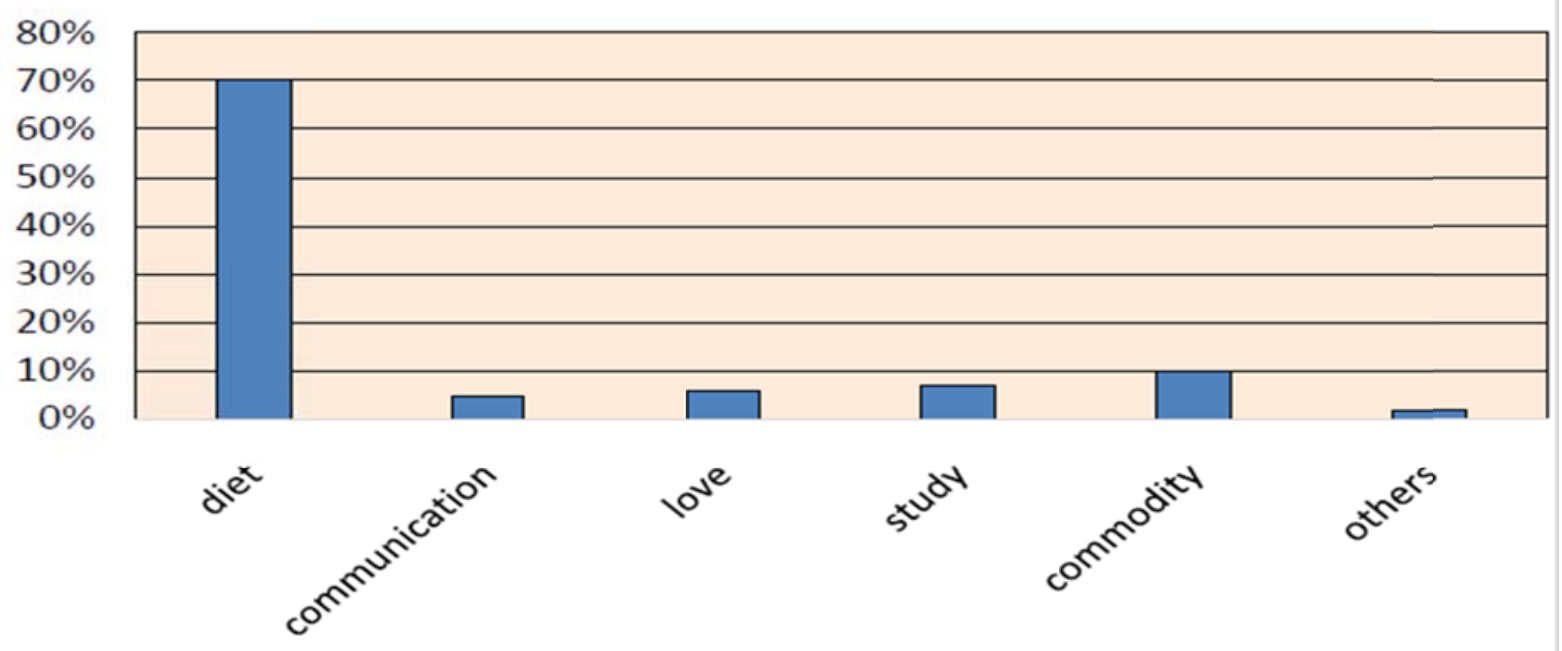

Fig. 1. The diet of expenditure living in the largest number

\subsection{The main source of income}

Social media has its social responsibility for education, if blindly to promote high consumption, aired ahead of consumption, to promote luxury consumption, which will inevitably result in a negative impact on college students. Therefore, the social level, the media should be more publicity of consumer attitudes, the basic theory of spending plans, consumption patterns, consumer psychology, consumer markets and consumer markets. Given the positive impact of new media, to help students recognize their own responsibilities and duties, and create a healthy environment for consumers. Survey data show that the main source of 88 percent of people are parents, who own $10 \%$ of part-time work-study, scholarships and other sources of each 1\%, as shown in Fig. 2.

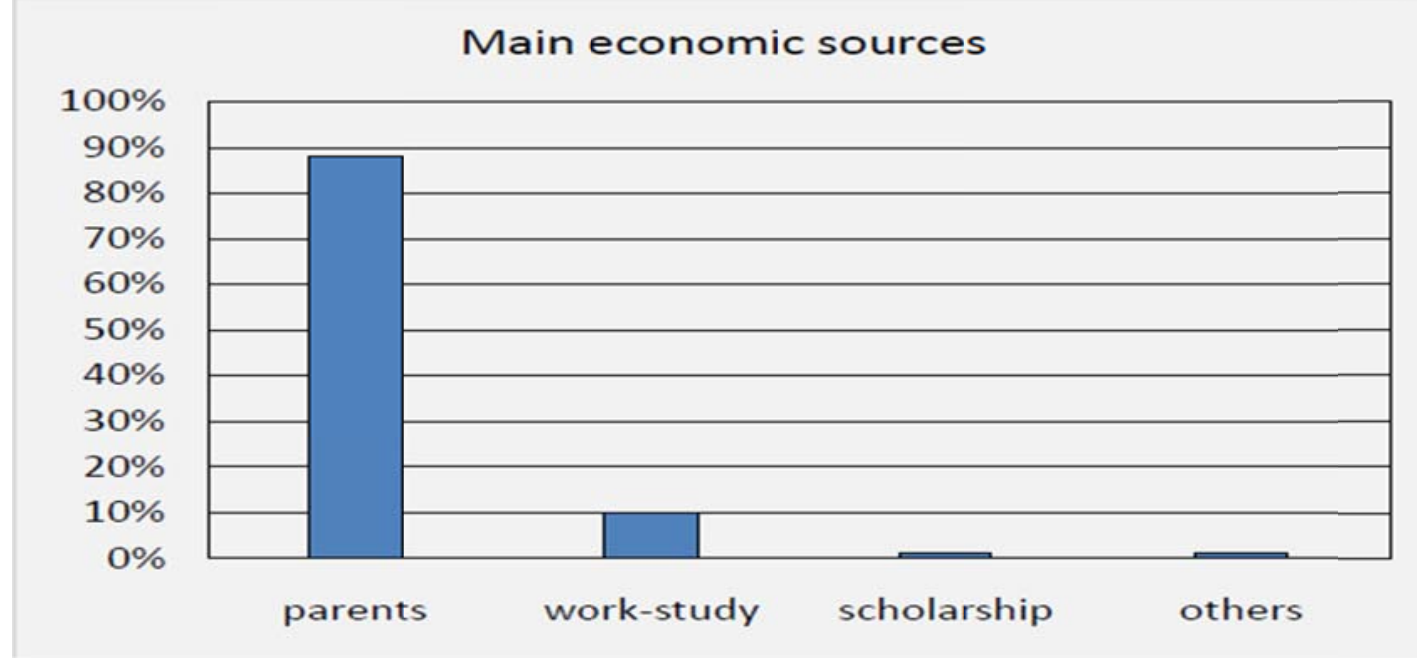

Fig. 2. Main economic sources 